American Journal of BioScience
2021; $9(3): 72-78$
http://www.sciencepublishinggroup.com/j/ajbio
doi: 10.11648 /j.ajbio.20210903.11
ISSN: $2330-0159$ (Print); ISSN: $2330-0167$ (Online)

\title{
Low-cost Rice Husk Ash and Silica for Chromium Ion Sorption from Aqueous System: Characterisation and Kinetics
}

\author{
Adelagun Ruth Olubukola Ajoke \\ Department of Chemical Sciences, Federal University Wukari, Wukari, Nigeria \\ Email address: \\ jemiruth2009@yahoo.com

\section{To cite this article:} \\ Adelagun Ruth Olubukola Ajoke. Low-cost Rice Husk Ash and Silica for Chromium Ion Sorption from Aqueous System: Characterisation \\ and Kinetics. American Journal of BioScience. Vol. 9, No. 3, 2021, pp. 72-78. doi: 10.11648/j.ajbio.20210903.11
}

Received: March 29, 2021; Accepted: April 20, 2021; Published: April 29, 2021

\begin{abstract}
Several materials have been developed and used to remove Chromate (VI) from industrial wastewater before discharge into the environment because of its toxicity and lethality. In this study, low-cost adsorbents (rice husk ash (RHA) and silica (RHS)) were prepared from rice husks purchased locally from a rice mill industry and characterised. While the crystallinity and mineralogy of the adsorbents were analysed using powdered XRD crystallography, analysis of the physicochemical properties was performed using standard procedures. Elemental analysis (CHN) was done using Perkin Elmer CHN elemental analyser and FTIR Spectrometer was used to determine the functional groups on the surface of the adsorbents at room temperature. The prepared samples were used as adsorbents for the removal of chromate (VI) ion in a batch sorption process with reaction conditions vis $-a-v i z$ adsorbent dosage $=0.5 \mathrm{~g}$, adsorbate volume $=500 \mathrm{ml}$, adsorbate solution concentrations: $10-200 \mathrm{mg} / \mathrm{l}$, time $=4 \mathrm{~h}$, temperature $=$ ambient temperature. The residual $\mathrm{Cr}(\mathrm{VI})$ concentration in the solution was analyzed spectrophotometrically at $\lambda=540 \mathrm{~nm}$ following the 1,5-diphenylcarbazide procedure. Results obtained for the characterisation of the adsorbents were similar and comparable with what obtained in literatures. Physico - chemical analysis revealed a high ash content of $89 \%$ and silica content of $95.83 \%$. XRD analysis for the rice husk ash samples reflected the presence of cristobalite $\left(\mathrm{SiO}_{2}\right)$ in amorphous form and a characteristics broad peak at $2 \theta$ angle $=26.5^{\circ}$. FTIR analysis revealed the presence of silanol groups ( $\mathrm{Si}-\mathrm{OH})$, silicic acid (Si-O-Si-OH) in the ash and Si-O-Si and Si-O) in the silica. The results of effect of time-concentration experiments of chromium ion sorption by the adsorbents revealed that $\mathrm{Cr}$ (VI) ion sorption was both time and initial solution concentration dependent with over $80 \%$ removal achieved within the first 30 min of contact for both adsorbents as the initial chromate concentration was increased. Kinetic modeling of the process showed up for pseudo second order, hinting on chemisorption as the mechanism of interaction.
\end{abstract}

Keywords: Characterisation, Chromium, Cristobalite, Kinetics, Rice Husk, Ash, Silica

\section{Introduction}

Chromate (VI) amelioration in industrial wastewater before discharge into the environment has become mandatory due to its lethality. The extensive use of chromate compounds in mining operations, electronic device manufacturing, power generation, tannery, metal plating and production of stainless steel has been reported to generate process water containing up to $10-100 \mathrm{mg} / \mathrm{L}$ of chromate [1]; much higher than limit of 0.1 $\mathrm{mg} / \mathrm{L}$ stipulated for industrial wastewater, thus requiring specialized or advance treatment for its removal. Chromium exhibits $+3,+6$ and 0 oxidation states in environmental matrix.
Hexavalent chromium is very mobile in the environment, speciated as dichromate, hydrogen chromate and chromate and a confirmed carcinogen and mutagen. Technological options of removal include chemical precipitation, membrane filtration, electrolysis and ion exchange. Conventionally, $\mathrm{Cr}^{6+}$ is removed by chemical reduction to the $\mathrm{Cr}^{3+}$ which is of lesser toxicity, and subsequent precipitation with a precipitant e.g. $\mathrm{NaOH}$. The aforementioned technologies while able to effectively meet the standards, are hampered by various factors such as consumption of chemical agents, huge cost, generation of large amount of sludge requiring disposal and ineffective for the removal of low concentration of pollutants. Adsorptive method 
for $\mathrm{Cr}$ (VI) abstraction in waste streams has gained acceptance by researchers in recent times due to its simplicity of operations, economics, high efficiency and availability of many arrays of cheap environmental - friendly adsorbents [2]. Many agro-based adsorbents have been applied with success for the treatment of chromium contaminated wastewater.

Table 1. Some Biosorbents Used for Cr (VI) Removal.

\begin{tabular}{lll}
\hline Adsorbents & $\mathbf{m g ~ C r}(\mathbf{V I}) / \mathbf{g}$ & Reference \\
\hline Potato peel & 3.28 & {$[3]$} \\
Sawdust & 3.6 & {$[4]$} \\
Rubber wood sawdust & 44.1 & {$[5]$} \\
Hazel nut shell & 17.7 & {$[6]$} \\
Groundnut husk & 11.4 & {$[7]$} \\
Aligator weed & 82.57 & {$[8]$} \\
\hline
\end{tabular}

Rice husk $(\mathrm{RH})$ is an agricultural wastes obtained during rice milling, and composed of both mineral and organic materials including cellulose, lignin silica, alkalis and trace element. Traditionally, rice husk is considered a waste material and generally disposed off by dumping or burning, although some are used as a low-grade fuel. However, the amounts of rice husk available are so far in excess of any local use and have posed environmental problem. The unique physical and chemical properties of RH such as granular structure, chemical stability, high ash and silica content, has promoted its use in domestic and industrial application [9]. Rice husk has been applied (directly or as rice husk ash) as a resource in the industry as a value added material or in manufacture and synthesis of new materials [10]. Controlled burning of rice husk at moderate temperature followed by acid leaching treatment yields rice husk ash (RHA) of high silica content ( $>$ $92 \%)$ of very high purity $[11,12]$. The high silica content in RHA has been employed for the production of silicon carbide, sodium silicate, zeolite and silica gel. Silica gels have been employed to remove heavy metals and organic pollutants from aqueous system [13-15]. Silica is a polymer of silicic acid made of inter-linked $\mathrm{SiO}_{4}$ repeating units in tetrahedral arrangement. The active silica surface with large specific surface area and surface hydroxyl groups have been credited to its importance in adsorption and ion exchange processes. On the outer surface of the silica structure, there are free silanol groups, referred to as isolated silanol groups, and hydrogen bonded to adjoining silanol groups referred to as vicinal or germinal silanol group [16]. In this work, we report the preparation and characterization of rice husk ash and silica from rice husk as well as the kinetic of the adsorption of chromate VI ion from aqueous solutions by these materials in a batch reactor. Elucidation of mechanism of interaction was undertaken through kinetic modeling of the data obtained.

\section{Materials and Methods}

\subsection{Materials}

(a) Preparation of Rice Husk Ash (RHA)

Rice Husks (RH) was obtained from a nearby rice mill, sieved to remove very fine particles, washed with deionized water and dried in an open air. Rice husk ash was prepared from the dried rice husk by acid leaching using nitric acid (Analar grade) followed by calcination in a muffle furnace (CARBOLITE, 5220). Acid leaching of the dried rice husks was done to remove soluble elemental impurities and to increase the purity of silica content. $50 \mathrm{~g}$ of the dried rice husks was soaked in $200 \mathrm{ml}$ of $0.1 \mathrm{M}$ nitric acid solution and heated at $80^{\circ} \mathrm{C}$ for $15 \mathrm{~min}$. Rice husk was filtered and rinsed several times with distilled water until neutral $\mathrm{pH}$ and dried at $100^{\circ} \mathrm{C}$ for $2 \mathrm{hr}$. The rice husk ash was obtained by pyrolysis of the acid leached rice husk in a muffle furnace at $700^{\circ} \mathrm{C}$ for $6 \mathrm{~h}$ in the form of a white- greyish powder.

\section{(b) Preparation of Rice Husk Silica (RHS)}

The chemicals and reagents used in the process were of analytical grade. Preparation of the rice husk silica was carried out thus: $35 \mathrm{~g}$ of rice husk ash was mixed with $250 \mathrm{ml}$ of $1 \mathrm{~N}$ sodium hydroxide aqueous solution. The mixture was refluxed for $3 \mathrm{~h}$ at $110^{\circ} \mathrm{C}$, filtered and stored in a refrigerator as sodium silicate. $50 \mathrm{ml}$ of sodium silicate solution was poured into 15 $\mathrm{ml}$ distilled water at a time and stirred. This was followed by drop wise titration with $3 \mathrm{M} \mathrm{H}_{2} \mathrm{SO}_{4}$ until a final $\mathrm{pH} 5$ under stirring speed to form rice husk silica. The acidic condition of pH 5 indicates approximately the complete precipitation of silica from sodium silicate by the following reaction:

$$
\begin{aligned}
& \mathrm{SiO}_{2}+2 \mathrm{NaOH} \rightarrow \mathrm{Na}_{2} \mathrm{SiO}_{3}+\mathrm{H}_{2} \mathrm{O} \\
& \text { Ash Sodium silicate } \\
& \mathrm{Na}_{2} \mathrm{SiO}_{3}+\mathrm{H}_{2} \mathrm{SO}_{4} \rightarrow \mathrm{SiO}_{2}+\mathrm{Na}_{2} \mathrm{SO}_{4}+\mathrm{H}_{2} \mathrm{O} \\
& \text { Sodium Silicate Silica }
\end{aligned}
$$

(C) Characterisation of adsorbents

The physico-chemical characterisation and proximate analysis of the samples (RHA and RHS) was carried out by following approved procedures. Elemental analysis (CHN) was done using Perkin Elmer CHN elemental analyser. FTIR Spectrometer (IR PRESTIGE 21, SHIMADZU) was used to determine the functional groups on the surface of RHA and RHS. Pellet pressed technique was used for this purpose at the spectral range of $4000-400 \mathrm{~cm}^{-1}$ with resolution of $4 \mathrm{~cm}^{-1}$. The adsorbents crystallinity and mineralogy was assessed using powdered XRD crystallography (XRD D8, ADVANCE BRUKER), using copper as the target, with $\mathrm{Ni}$ as the filter media and $\mathrm{K}$ radiation maintained at $1.54 \mathrm{~A}$. Diffraction patterns of the samples were recorded in the range of $10-90^{\circ}$ at a scanning rate of $2 \% \mathrm{~min}$ and step size of 0.01 .

\subsection{Methods}

(a) Preparation and analysis of adsorbate

A stock solution of hexavalent chromium (1000 mg/L) was prepared in a double distilled deionized water using potassium dichromate $\left(\mathrm{K}_{2} \mathrm{Cr}_{2} \mathrm{O}_{7}\right)$. Working solutions of varying concentrations $(10-200 \mathrm{mg} / \mathrm{L})$ were obtained by serial dilution of the stock solution. The residual $\mathrm{Cr}$ (VI) concentration in the supernatant was determined using a UV - visible spectrophotometer (UV-1601, Shimadu) at $\lambda_{\max }=$ $540 \mathrm{~nm}$, following the 1,5-diphenylcarbazide procedure.

(b) Data analysis 
The amount of chromium removed by the RHA and RHS samples $(\mathrm{mg} / \mathrm{g})$ was calculated using the equations:

$$
\begin{gathered}
\text { Amount of } \mathrm{Cr}(\mathrm{VI}) \text { sorbed per mg of adsorbent }=\frac{c_{o-c_{e}}}{w} \times v \\
\text { Percentage } \mathrm{Cr}(\mathrm{VI}) \text { removal }=\frac{c_{o}-c_{e}}{c_{o}} \times 100
\end{gathered}
$$

Where $c_{o}$ is the initial concentration of adsorbate $(\mathrm{mg} / \mathrm{L}), \mathrm{c}_{\mathrm{e}}$ is the equilibrium concentration of adsorbate $(\mathrm{mg} / \mathrm{L}), v$ is the volume of the solution ( $\mathrm{ml})$ and $w$ is the mass of the adsorbent $(\mathrm{g})$.

(C) Adsorption Experiments

All sorption studies were done and carried out at $25^{\circ} \mathrm{C}$. Adsorbate solution $\mathrm{pH}$ was corrected to 5.3 using $0.1 \mathrm{M}$ $\mathrm{HNO}_{3}$ and $\mathrm{NaOH}$ for the entire reaction.

Effect of Initial Solution Concentration

This was done by contacting $0.5 \mathrm{~g}$ of the RHA and RHS samples with $500 \mathrm{ml}$ of varying concentrations of the adsorbate $\left(\mathrm{Cr}^{6+}\right)$ solution that ranged between $10-200 \mathrm{mg} / \mathrm{L}$ in a batch reactor. The system was agitated on a magnetic stirrer at a speed of $200 \mathrm{rpm}$. Solution samples were withdrawn with a syringe after $4 \mathrm{hr}$ of contact filtered using $0.45 \mu \mathrm{m}$ membrane filter centrifuged and the supernatant was analysed for residual $\mathrm{Cr}$ (VI) as previously described.

Effect of Time

The time-concentration profiles of the sorption of the adsorbate by the samples was studied to obtained the kinetic parameters by contacting $2 \mathrm{~g}$ of adsorbent sample to $1000 \mathrm{ml}$ of adsorbate solution of varying initial concentrations (10$200 \mathrm{mg} / \mathrm{L}$ ) in a batch reactor. The system was agitated on a magnetic stirrer at a speed of $200 \mathrm{rpm}$. Solution samples were withdrawn with a syringe at intervals between 0 and 4 $\mathrm{hr}$ of contact, filtered using $0.45 \mu \mathrm{m}$ membrane filter, centrifuged and the supernatant was analysed for residual $\mathrm{Cr}$ (VI) as previously described.

\section{Results and Discussion}

\subsection{Physical and Chemical Characterisations of RHA and RHS Samples}

Results of the proximate analysis of RHA presented in Table 2 showed its high ash content thus indicating the highly inorganic nature of RHA with silica content of $95.83 \%$. The values obtained for the physicochemical parameters for the RHS prepared in this study are similar and compare favourably with what obtained in literatures $[16,17]$.

\subsection{Instrumental Characterisation via FTIR and XRD Analysis of RHA and RHS Samples}

In the FTIR spectral of the RHA (Figure 1), the peak between $2830-3720 \mathrm{~cm}^{-1}$ and $3440-2900 \mathrm{~cm}^{-1}$ were ascribed to the presence of $\mathrm{OH}$ and $\mathrm{Si}-\mathrm{OH}$ groups on the RHA surface. The band at $3430 \mathrm{~cm}^{-1}$ pertained to the silanol group and water adsorbed on the surface of RHA $[18,19]$. The structure of the silanol groups are similar to that of silicic acid and are in form of silicon dioxide structure (Si-O-Si-OH) [16]. The weak broad peaks around 1600 $\mathrm{cm}^{-1}$ corresponded to stretching of ketonic $(\mathrm{C}=\mathrm{O})$ and aldehydic $(\mathrm{C}-\mathrm{OH})$ groups. The presence of other organics groups were indicated at $2940-1300 \mathrm{~cm}^{-1}$, for instance, the bands observed between $2920-2855 \mathrm{~cm}^{-1}$ and at $1423 \mathrm{~cm}^{-1}$ corresponded to the presence of methyl groups and aromatic rings due to the presence of lignin, respectively [18]. The peak at $1100 \mathrm{~cm}^{-1}$ is ascribed to Si$\mathrm{O}-\mathrm{Si}$ and $-\mathrm{C}-\mathrm{O}-\mathrm{H}$ stretching and $\mathrm{OH}$ deformation while peaks at $793 \mathrm{~cm}^{-1}$ and $469 \mathrm{~cm}^{-1}$ suggest the presence of $\mathrm{Si}-\mathrm{H}[17,19]$. FTIR analysis of the RHS presented in Figure 1 showed a little broad band between $3380 \mathrm{~cm}^{-1}$ and $3240 \mathrm{~cm}^{-1}$ is ascribed to the hydroxyl group of both the silanol groups and water molecules bonded to the silica surface of RHS. Characteristic peak detected at $1647 \mathrm{~cm}^{-1}$ pertained to the bonding vibration of water molecule trapped in the $\mathrm{SiO}_{2}$ matrix. Notable silica peaks were detected at $1014 \mathrm{~cm}^{-1}, 989 \mathrm{~cm}^{-1}$ for (Si-O-Si) and $866 \mathrm{~cm}^{-1}$ and $478 \mathrm{~cm}^{-1}$ for (Si-O) groups, respectively.

Table 2. Physicochemical Properties of RHA Samples.

\begin{tabular}{ll}
\hline Parameters & Amount (\%) \\
\hline Proximate Analysis & \\
Ash content & 89 \\
Moisture & 0.69 \\
Volatile Matter & 5.6 \\
Fixed Carbon & 6.2 \\
Inorganic Composition & \\
$\mathrm{SiO}_{2}$ & 95.83 \\
$\mathrm{MgO}_{\mathrm{Fe}} \mathrm{O}_{3}$ & 0.50 \\
$\mathrm{CaO}_{\mathrm{Al}} \mathrm{O}_{3}$ & 0.19 \\
Elemental analysis (CHN) & 0.33 \\
$\mathrm{Carbon}_{\mathrm{Hydrogen}}$ & 0.39 \\
Nitrogen and others & \\
\hline
\end{tabular}
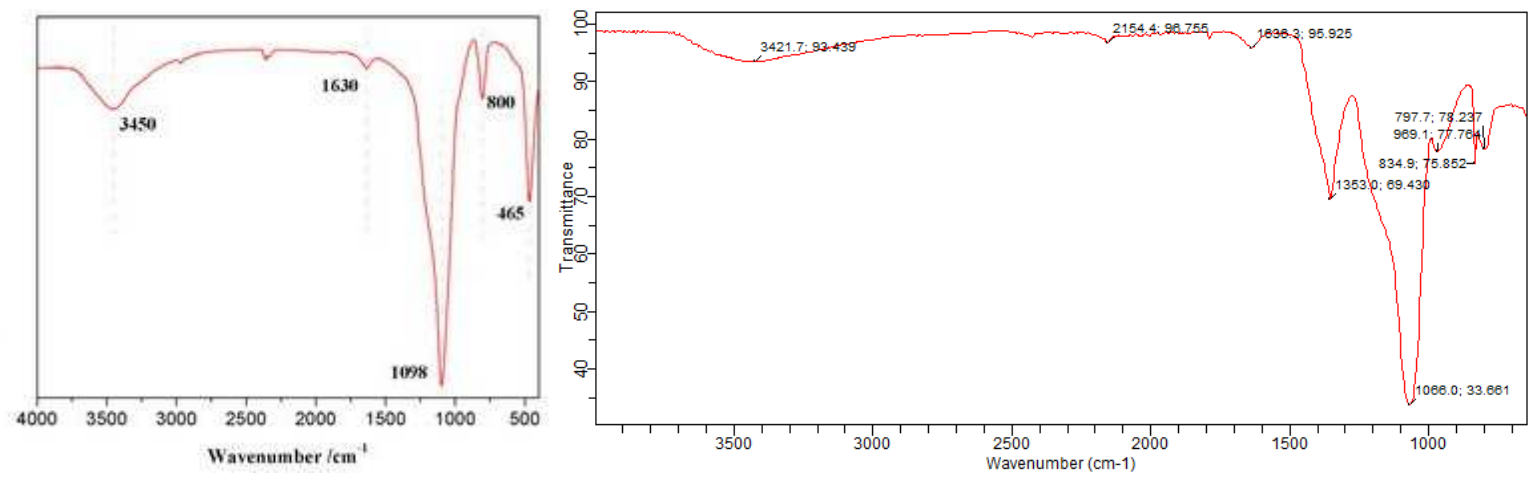

Figure 1. (a) FTIR Pattern of RHA, (b) FTIR Pattern of RHS. 
The XRD spectra of the RHA and RHS are presented in Figure $2 a$ and $2 b$, respectively. The spectrum of the RHA indicated a highly amorphous material with the broad peak spanning $2 \theta$ angle range of $18-30^{\circ}$ confirms an amorphous form of silica. RHA presented lower crystallinity than RHS. The spectrum of the RHS indicated a crystalline material with a sharp notable characteristic silica peak at $2 \theta=26.5^{\circ}$. This change in texture from amorphous to crystalline phase is attributed to the calcination of the material in temperature above $500^{\circ} \mathrm{C}[17,19]$. The value of the distance between the basal interlayer $(d)$ was calculated using Bragg's law:

$$
d=\frac{\lambda}{2 \sin \theta}
$$

$d$ is the interlayer distance between planes of atoms; $\theta$ is diffraction angle; $\lambda(1.542 \AA)$ is wave length. The incidence

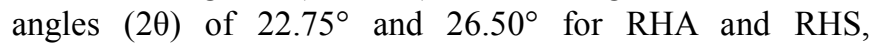
respectively gives basal interlayer distances $(d)$ of 4.23 and $4.99 \AA$, respectively. The d-spacing depends upon size and orientation of the charge balancing ion. The mineralogical classification of the RHS indicated the presence of cristobalite [20] and presence of cristobalite $\left(\mathrm{SiO}_{2}\right)$, Magaritasite and Macedonite for RHA.

\subsection{Adsorption Experiments}

Effect of Initial Chromate Solution Concentration $\left(C_{o}\right)$
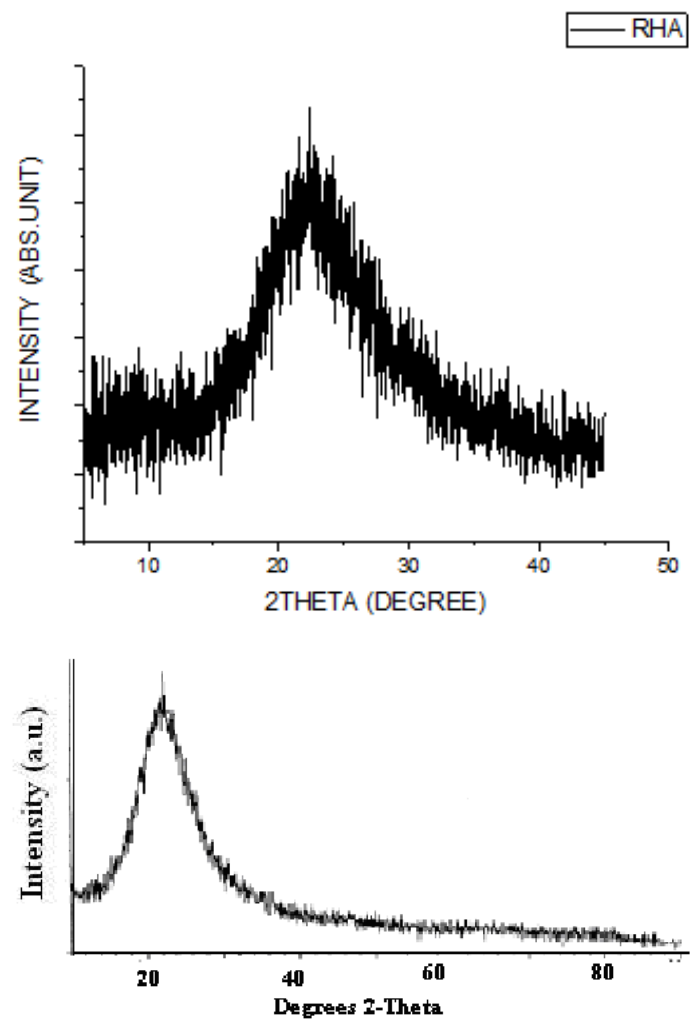

Figure 2. (a) XRD Diffractogram of RHA, (b) XRD Diffractogram of RHS.

The result of effect of initial solution concentration on hexavalent chromium ion removal (\%) by RHA and RHS sample is shown in Table 3. It was observed that chromate removal from the aqueous system is dependent on and increases with initial solution concentration. That is, the amount of $\mathrm{Cr}$ (VI) ions sorbed per unit mass of the adsorbents increases with increase in initial adsorbate concentration. As the $C_{o}$ was increased from $10-200 \mathrm{mg} / \mathrm{L}$, the amount (\%) of $\mathrm{Cr}^{6+}$ removed increased from $5 \%$ to $75 \%$ for RHA and $17 \%$ to $90 \%$ for RHS. The reason given for this observed trend is that the driving force needed to overcome resistance to the mass transfer of $\mathrm{Cr}$ ions between the aqueous and solid phases was increased by the increase in adsorbate initial solution concentration. Thus, as the $C_{o}$ increases, it enhances interaction that led to the adsorption uptake of the chromate ions by the adsorbents. Consequently, an increase in the initial chromate concentration increased the amount of $\mathrm{Cr}^{6+}$ removed per gram of the RHS/RHA samples. At the initial concentration of $10 \mathrm{mg} / \mathrm{L}$, the efficiency ranged between $3.67-5.15 \%$ whereas at $200 \mathrm{mg} / \mathrm{L}$ initial chromate concentration, efficiency ranged between $32.56-74.87 \%$ for RHA while it was $17.62-36.46 \%$ for $10 \mathrm{mg} / \mathrm{L}$ and $39.10-$ $90.91 \%$ for RHS after $4 \mathrm{~h}$ of contact time.

Table 3. Percentage Chromate Removal by Adsorbents.

\begin{tabular}{lllll}
\hline Concentration (mg/L) & $\mathbf{1 0}$ & $\mathbf{5 0}$ & $\mathbf{1 0 0}$ & $\mathbf{2 0 0}$ \\
\hline \% Removal by RHA & 5 & 15 & 37 & 75 \\
\% Removal by RHS & 17 & 38 & 75 & 90 \\
\hline
\end{tabular}

Effect of Contact Time on sorption of Cr (VI)

This was conducted between a time range of $0-4 \mathrm{~h}$ by contacting $2 \mathrm{~g}$ of the adsorbent samples with $2 \mathrm{~L}$ of adsorbate solution of different concentrations $(10-200 \mathrm{mg} / \mathrm{L})$ in a batch reactor. The results of the time-concentration profiles presented in Figure 3 and Figure 4 showed that chromate (VI) ions removal by RHA and RHS, respectively were clearly time dependent. The sorption rate of the adsorbate by the adsorbents was very rapid during the initial $15 \mathrm{~min}$ of contact, and thereafter slowed down. This was seen in the gradual approach of the state of equilibrium after the first 120 min period of the process. No appreciable adsorbate sorption was observed thereafter. Values up to $80 \%$ of the total chromate removed was obtained within the first $60 \mathrm{~min}$ of the process followed by an additional $20 \%$ removal after $90 \mathrm{~min}$ of contact time and then values less than $3 \%$ additional $\mathrm{Cr}$ (VI) removal occurred in the remaining $120 \mathrm{~min}$ of contact time. At the commencement of the process, there existed large number of vacant active sites on the adsorbent surface available for adsorption, these accounted for the initial rapid uptake of $\mathrm{Cr}$ observed at the inception of the sorption process. These active sites become saturated after the lapse of some time which results in the slowing down of the adsorbate removal during the later period of adsorption and eventual repulsion between the solute molecules on the solid surface and the bulk solution [21]. For the present study the equilibrium time of $120 \mathrm{~min}$ could be considered economically favourable for the sorption process. 


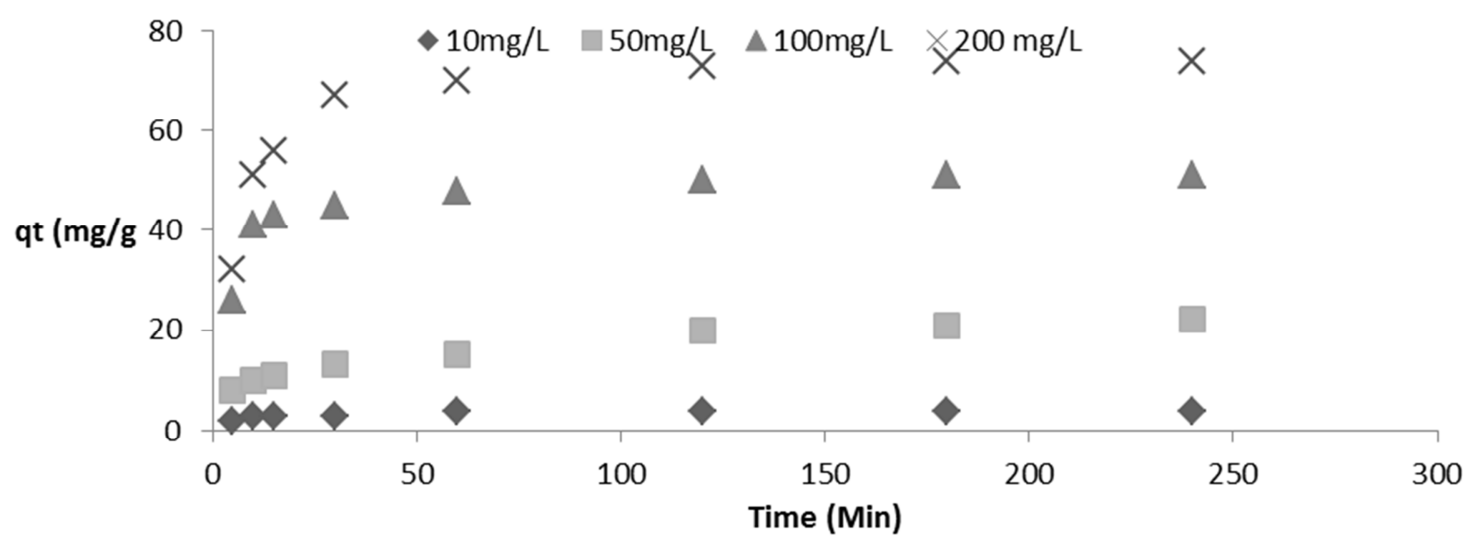

Figure 3. Effect of Contact Time on Cr Removal by RHA.

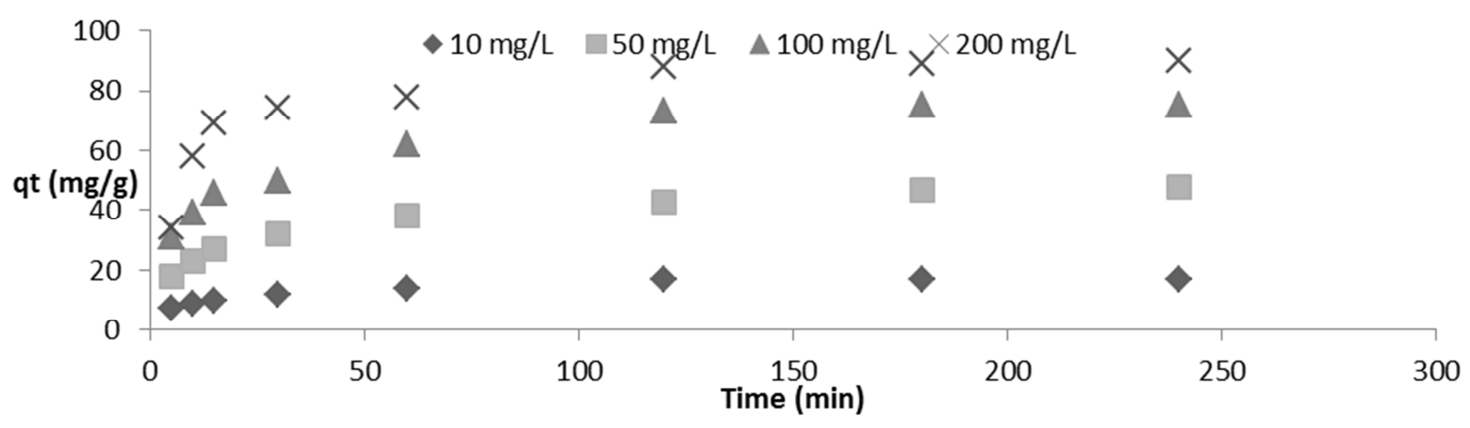

Figure 4. Effect of Contact Time on Cr Removal by RHS.

Kinetic Modeling of the Sorption Process

Kinetics of adsorption as a dynamic process is usually used to describe rate as well as mechanism of adsorbate uptake from the solution by the adsorbent. Data obtained from the kinetic studies of adsorbate uptake is used in selecting optimum operating conditions for the full scale batch process. Elucidation of the mechanism of $\mathrm{Cr}$ (VI) sorption by the RHA/RHS was studied with the aid of frequently used kinetic models. The data obtained from the time-concentration profile were fitted into the equations of the model: Lagergren pseudo-first order and pseudo-second order. The Lagergren pseudo first-order kinetic model is represented as:

$$
\frac{d q_{t}}{d t}=k_{i}\left(q_{e}-q_{t}\right)
$$

On integration gives the linear form expressed as:

$$
\log \left(q_{e}-q_{t}\right)=\log q_{e}-\frac{k 1_{t}}{2.303}
$$

Where $q_{e}$ and $q_{t}$ are the sorption capacity at equilibrium and time $t$ respectively $(\mathrm{mg} / \mathrm{g}) . k_{l}$ is the rate constant of pseudo -first order adsorption $\left(\mathrm{min}^{-1}\right)$. A plot of $\log \left(q_{e^{-}} q_{t}\right)$ against $t$ gave a linear relationship from where the pseudo first order parameters $\left(k_{1}\right.$ and $\left.q_{e}\right)$ were determined from the slope and intercept, respectively. The pseudo - first order parameters obtained from the plots for $\mathrm{Cr}$ (VI) sorption by RHA are presented in Table 4. The pseudo second order kinetic model considers the rate - limiting step as the formation of a chemisorption bond as well as exchange or sharing of electrons between the sorbate and sorbent [22]. The non linear form is expressed as:

$$
\frac{d q_{t}}{d t}=k_{2}\left(q_{e}-q_{t}\right)^{2}
$$

The linear form is expressed as:

$$
\frac{t}{q_{t}}=\frac{1}{k_{q_{e}}}+\frac{1}{q_{e}} \mathrm{t}
$$

Where $k$ is the overall rate constant of pseudo-second order sorption $((\mathrm{g} / \mathrm{mg}) / \mathrm{min})$. The plot of $t / q t$ against $t$ gives a linear relationship, from which $q e$ and $k$ could be determined from the slope and intercept, respectively. The pseudo - second order parameters obtained from the plots for CR (VI) sorption by RHS are presented in Table 5. Establishment of the better model amongst the two was carried out thus: i. From the results presented in Tables 4 and 5, it could be deduced that values of $q_{e}$ calc obtained for the pseudo second order were closer in magnitude to the experimental data than what was obtained for the pseudo first order model ii. the values of $\mathrm{R}^{2}$ obtained for the pseudo second order plot were very high, $\left(\mathrm{R}^{2}>0.99\right)$ compared to pseudo first order. Thus, it could be concluded that the pseudo second order model describes adequately the sorption process. This therefore implies that the mechanism of sorption of chromium (VI) on the adsorbents (RHA and RHS) was chemisorption. 
Table 4. Kinetics Models Parameters of Chromium (VI) sorption on RHA.

Pseudo First Order Model

\begin{tabular}{lllll}
\hline co $(\mathbf{m g} / \mathbf{L})$ & $\mathbf{q}_{\text {e exp. }}(\mathbf{m g} / \mathbf{g})$ & $\mathbf{q}_{\text {el cal. }}(\mathbf{m g} / \mathbf{g})$ & $\mathbf{K}_{\mathbf{1}}\left(\mathbf{g m g}^{-1} \mathbf{m i n}^{-1}\right)$ & $\mathbf{R}^{\mathbf{2}}$ \\
\hline 10 & 6.121 & 2.329 & 0.0154 & 0.874 \\
50 & 25.970 & 7.710 & 0.0306 & 0.777 \\
100 & 50.667 & 10.552 & 0.0289 & 0.894 \\
200 & 78.63 & 14.389 & 0.0175 & 0.634 \\
\hline
\end{tabular}

Second Order Model

\begin{tabular}{|c|c|c|c|c|}
\hline co $(\mathrm{mg} / \mathrm{L})$ & $q_{e \text { exp. }}(\mathrm{mg} / \mathrm{g})$ & 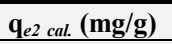 & $K_{2}\left(g g^{-1} \min ^{-1}\right)$ & $\mathbf{R}^{2}$ \\
\hline 10 & 6.121 & 5.45 & 0.126 & 0.992 \\
\hline 50 & 25.970 & 29.99 & 0.199 & 1.000 \\
\hline 100 & 50.667 & 49.25 & 0.314 & 0.997 \\
\hline 200 & 78.63 & 73.77 & 0.200 & 0.999 \\
\hline
\end{tabular}

Table 5. Kinetics Models Parameters of Chromium (VI) sorption on RHS.

Pseudo First Order Model

\begin{tabular}{llll}
\hline co $(\mathbf{m g} / \mathbf{L})$ & $\mathbf{q}_{\text {exp. }}(\mathbf{m g} / \mathbf{g})$ & $\mathbf{q}_{\text {e1 cal. }}(\mathbf{m g} / \mathbf{g})$ & $\mathbf{K}_{\mathbf{1}}\left(\mathbf{g m g}^{-1} \mathbf{m i n}^{-1}\right)$ \\
\hline 10 & 7.221 & 1.101 & 0.0154 \\
50 & 34.700 & 8.716 & 0.0306 \\
100 & 66.661 & 11.152 & 0.0289 \\
200 & 108.23 & 34.119 & 0.0175 \\
\hline
\end{tabular}

Second Order Model

\begin{tabular}{lllll}
\hline co $(\mathbf{m g} / \mathbf{L})$ & $\mathbf{q}_{\text {exp. }}(\mathbf{m g} / \mathbf{g})$ & $\mathbf{q}_{\text {e2 cal. }} \mathbf{( m g / g )}$ & $\mathbf{K}_{\mathbf{2}}\left(\mathbf{g m g} \mathbf{g m i n}^{-1}\right)$ & \\
\hline 10 & 7.221 & 7.45 & 0.249 & \\
50 & 34.700 & 31.69 & 0.432 & 0.999 \\
100 & 66.661 & 66.85 & 0.351 & 1.000 \\
200 & 108.203 & 103.43 & 0.447 & 0.997 \\
\hline
\end{tabular}

Estimation of Sorption Performance

A parameter $k_{2} q e\left(\mathrm{~min}^{-1}\right)$ defined as the second order rate index was used to define the kinetic performance as described by Wu et al., [23].

At the half-life of the sorption process,

$$
\mathrm{q}_{\mathrm{t}}=0.5 \mathrm{qe}
$$

and

$$
t_{0.5}=\frac{1}{k_{2} q_{e}}
$$

Using equation (11), results obtained presented in Table 6 showed that increase in the initial concentrations of chromate ion in solution led to a reduction in the values of the half-life of the sorption process. This indicates therefore increase in initial adsorbate concentration brings about a lowering of the time needed to reduce it to half its initial amount.

Table 6. Sorption performance of RHA for Cr (VI) removal.

\begin{tabular}{lllll}
\hline Parameters & $\mathbf{1 0} \mathbf{~ m g / l}$ & $\mathbf{5 0} \mathbf{~ g / / ~}$ & $\mathbf{1 0 0} \mathbf{~} \mathbf{g} / \mathbf{l}$ & $\mathbf{2 0 0} \mathbf{~ m g / \mathbf { l }}$ \\
\hline$k_{2} q_{e}\left(\mathrm{~min}^{-1}\right)$ & 2.218 & 7.33 & 6.080 & 25.13 \\
$t_{0.5}$ & 0.854 & 0.667 & 0.426 & 0.247 \\
\hline
\end{tabular}

Table 7. Sorption performance of RHS for Cr (VI) removal.

\begin{tabular}{lllll}
\hline Parameters & $\mathbf{1 0} \mathbf{~} \mathbf{g} / \mathbf{l}$ & $\mathbf{5 0} \mathbf{~ m g} / \mathbf{l}$ & $\mathbf{1 0 0} \mathbf{~ m g} / \mathbf{l}$ & $\mathbf{2 0 0} \mathbf{~ m g / \mathbf { l }}$ \\
\hline$k_{2} q_{e}\left(\mathrm{~min}^{-1}\right)$ & 5.510 & 14.072 & 36.08 & 50.13 \\
$t_{0.5}$ & 0.254 & 0.167 & 0.066 & 0.034 \\
\hline
\end{tabular}

\section{Conclusion}

Based on the findings in this work, it is justifiable that both RHA and RHS can be used for the abstraction of $\mathrm{Cr}$ (VI) ions from contaminated effluents. The following deductions were drawn:

XRD analysis revealed the presence of cristobalite $\left(\mathrm{SiO}_{2}\right)$, Magaritasite and Macedonite in RHA and cristobalite in RHS, respectively.

FTIR analysis revealed that functional groups such as -
$\mathrm{OH},-\mathrm{C}-\mathrm{OH}, \mathrm{C}=\mathrm{O}$, Si-O-Si and $\mathrm{Si}-\mathrm{H}$ are present on the RHA and RHS surfaces.

Kinetics study showed that sorption is favourably influenced by increase in initial adsorbate concentration and time.

Kinetic modeling followed the pseudo second order rate expression, a hint on chemisorption as mechanism of interaction.

The equilibrium time of $120 \mathrm{~min}$ is favourable economically for hexavalent chromate adsorption by RHS 
and RHA from aqueous system.

The adsorption rate of RHS is higher than that of RHA.

Both RHS and RHA are effective adsorbents for the removal of $\mathrm{Cr}$ (VI) from aqueous solution.

\section{References}

[1] Kameda, T., Kondo E. and Yoshioka T. (2014). Preparation of $\mathrm{Mg}-\mathrm{Al}$ layered double hydroxide doped with $\mathrm{Fe}^{2+}$ and its application to Cr (VI) removal. Sep. and Purif. Tech. 122: 1216.

[2] Li, Y.; Gao, B.; Wu, T.; Sun, D.; Li, X.; Wang, B.; Lu, F. (2009). Hexavalent chromium removal from aqueous solution by adsorption on aluminum magnesium mixed hydroxide. Water Res. 43, 3067-3075.

[3] Mutongo F., Kuipa O., and Kuipa P. K. (2014). Removal of Cr (VI) from Aqueous Solutions Using Powder of Potato Peelings as a Low Cost Sorbent. Bioinorganic Chemistry and Applications 7 pages http://dx.doi.org/10.1155/2014/973153

[4] Baral, S. S., Das, S. N., \& Rath, P. (2006). Cr (VI) removal from aqueous solution by adsorption on treated sawdust. Biochemical Engineering Journal, 31 (3), 216-222.

[5] Karthikeyan, T., Rajgopal, S., \& Miranda, L. R. (2005). Chromium (VI) adsorption from aqueous solution by Hevea brasiliensis sawdust activated carbon. Journal of Hazardous Materials, 124 (1-3), 192-199.

[6] Cimino, G., Passerini, A., \& Toscano, G. (2000). Removal of toxic cations and $\mathrm{Cr}(\mathrm{VI})$ from aqueous solution by hazelnut shell. Water Research, 34 (11), 2955-2962.

[7] Dubey, S. P., \& Gopal, K. (2007). Adsorption of chromium (VI) on low cost adsorbents derived from agricultural waste material: a comparative study. Journal of Hazardous Materials, 145 (3), 465-470.

[8] Wang, X. S.; Tang, Y. P.; Tao, S. R. (2008). Removal of Cr (VI) from aqueous solutions by the non-living biomass of alligator weed: Kinetics and equilibrium. Adsorption, 14 (6), $823-830$

[9] Shwetha, M. K.., Geethanjali H. M. and Chowdary K. (2014). A great opportunity in prospective management of rice husk. International Journal of Commerce and Business Management. 7 (1): 176-180.

[10] Yadav, J. P., and Singh, B. R. (2011). Study on comparison of boiler efficiency using husk and coal as fuel in rice mill. SAMRIDDHI-A Journal of Physical Sciences, Engineering and Technology. 2: 2229-7111.
[11] Lata, S., and Samadder, R. (2014). Removal of heavy metals using rice husk: a review. International Journal of Environmental Research and Development. 4: 165-170.

[12] Babaso, P. N. and Sharanagouda H. (2017). Rice Husk and Its Applications: Review International Journal of Current Microbiology and Applied Sciences. 6 (1): 1144-1156.

[13] Imyim, A., and Prapalimrungsi, E. (2010). Humic acids removal from water by aminopropyl functionalized rice husk ash. Journal of Hazardous Materials. 184 (1): 775-781.

[14] Sharma, P., Kaur, R., Chinnappan, B. and Chung, W. J. (2010). Removal of methylene blue from aqueous waste using rice husk and rice husk ash. Desalination 259 (1): 249-257.

[15] Malhotra, C., R. Patil, S. Kausley and Ahmad, D. (2013). Novel uses of rice-husk-ash (a natural silica-carbon matrix) in low-cost water purification applications. AIP Conference Proceeding.

[16] Nakbanpote, W., P. Thiravetyan and Kalambaheti, C. (2000). Preconcentration of gold by rice husk ash. Mining engineering. 13 (4): 391-400.

[17] Srivastava V. C., Prasad B., Mall I. D., Mahadevswamy M., and Mishra I. M. (2006). Adsorptive removal of phenol by baggasse fly ash and activated carbon: equilibrium, kinetic and thermodynamics. Colloids Surface A: Physicochem. Eng. Aspect 272: 89-104.

[18] Tarley, C. R. T. and Arruda, M. A. Z. (2004). Biosorption of heavy metals using rice milling by-products. Characterization and application for removal of metals from aqueous effluents. Chemosphere, 54, 987-995.

[19] Nakbanpote, W., Goodman, B. A. and Thiravetyan, P. (2007). Cooper adsorption on rice husk derived materials studied by EPR and FTIR. Colloids Surf., A. 304, 7-13.

[20] Geetha, D., Ananthiand, A. and Ramesh, P. S. (2019). Preparation and Characterization of Silica Material from Rice Husk Ash - An Economically Viable Method. J. of Pure and Applied Physics 4 (3): 20-27.

[21] Adelagun R. O. A. (2018). Adsorption of Tetracycline by a Tailor- made Adsorbent in Aqueous System. Open Access Journal of Chemistry (2) 4: 45-52.

[22] Ho Y. S., and McKay G. 1998. Pseudo second order model for sorption processes. Process Biochem. 34: 451-465.

[23] Wu F. C., Tseng, R. L., and Juang R. S. (2009). Initial behavior of intraparticle diffusion model used in the description of adsorption kinetics, Chem. Eng. J. 153: 1-8. 